\title{
Relationship between invertebrate traits and lateral environmental gradients in a Mediterranean river-floodplain
}

\author{
Belinda Gallardo 1, *, Stephanie Gascón², Álvaro Cabezas', María Gonzalez', \\ Mercedes García ${ }^{1}$ and Francisco A. Comín ${ }^{1}$
}

With 5 figures and 4 tables

\begin{abstract}
The aim of the present study was to describe the relationships between macroinvertebrate traits and lateral hydrological and environmental gradients in a Mediterranean river-floodplain, from the main river channel to three disconnected floodplain wetlands. Bimonthly water and macroinvertebrate samples were collected from an array of riverine wetlands in the Ebro River in northeast Spain. Our analysis of trait structures in wetlands aligned along a lateral hydrological gradient showed that community composition changed from a rich and abundant invertebrate community dominated by generalist species adapted to disturbance at the river site to a more trait-diversified community of specialist species adapted to stability and biotic interaction in hydrologically disconnected floodplain sites. The diversity of functional groups peaked at intermediate-connected sites, where both generalist and specialist species coexist. The highest richness of functional groups was found in the river site, reflecting its highest habitat heterogeneity. The main environmental variables shaping the structure of invertebrate traits extracted after Redundancy Analysis were flood duration and frequency (surrogates of hydrological disturbance), dissolved solids (surrogate of confinement) and nitrate concentration (surrogate of agricultural pressure). These environmental variables explained $43 \%$ of the existing variability in invertebrate traits. Because groups with similar traits responded in different ways to the main gradients, we conclude that the functional grouping of invertebrates provides an adequate and simple tool to assess changes in functionality and the effect of lateral gradients across a floodplain. Our results highlight the need to integrate the study of rivers and their floodplains to better account for their close interaction.
\end{abstract}

Key words: biological traits, lateral hydrological connectivity, hydrological disturbance, confinement, agricultural pressure, functional diversity.

\section{Introduction}

Aquatic community structure is determined by both abiotic factors, such as hydrological disturbance and water chemistry, and biotic effects resulting from ecological interaction - principally competition and predation (Batzer \& Wissinger 1996, Wellborn et al. 1996). Abiotic factors determine the potential habitat available for a particular species while biotic interactions determine a species' actual distribution (Well- born et al. 1996). Abiotic factors, in turn, may reflect natural gradients, such as climate, geology or hydrology, or may be the result of human alterations, such as river embankments, and agricultural, urban or industrial sewage. Life-history strategies and habitat use of organisms inhabiting freshwater systems integrate actual and historical conditions, and are comparable across different taxonomic groups; thus, these factors provide a unified measure of ecosystem constraints and interaction across communities with different

\footnotetext{
${ }^{1}$ Authors' addresses: Pyrenean Institute of Ecology (CSIC), Avda. Montañana, 1005, 50192 Zaragoza, Spain.

${ }^{2}$ Institute of Aquatic Ecology, Faculty of Sciences, University of Girona, Spain.

* Corresponding author; e-mail: belinda@ipe.csic.es
} 
taxonomic composition (Statzner 2001, Gayraud et al. 2003). Moreover, biological traits are especially telling with respect to ecosystem functionality, biodiversity and environmental alteration. For these reasons, bio-monitoring tools for assessing river alteration in large European rivers have recently focused on biological traits (e.g., Doledec et al. 1999, Gayraud et al. 2003, Bady et al. 2005, Statzner et al. 2005, Doledec \& Statzner 2008).

A number of environmental gradients reflecting hydrological patterns, habitat characteristics and water chemistry have been identified as important for aquatic invertebrates in river-floodplain ecosystems (Junk 1989, Tockner et al. 1999). Floodplain wetlands outside the river habitat (e.g., backwaters, oxbow lakes, temporary ponds) are lentic habitats arranged in a lateral hydrological connectivity gradient that become temporarily lotic during river pulses (Amoros \& Roux 1988, Ward \& Stanford 1995). The position of wetlands on that hydrological gradient is determined by the distance to the river, groundwater seepage and natural or artificial barriers to river flow (Amoros \& Bornette 2002). Dissolved salts and organic nutrients introduced by groundwater seepage, runoff and autogenic processes, accumulate in disconnected floodplain wetlands (i.e., those with low connectivity) (Tockner et al. 1999), leading to salinization and eutrophication. In addition, as floodplain areas have become extensively occupied, wetlands with low connectivity and high confinement are increasingly vulnerable to the accumulation of pollutants and nutrients generated by human activities. Among these nutrients, nitrate is the most common form in agriculture watersheds and is often used to assess water quality and ecological integrity of wetland ecosystems (Smith et al. 2007).

The dynamics governing the interplay of hydrological connectivity with environmental gradients and human pressure on rivers and their floodplains are difficult to measure directly (Galat et al. 1998, Tockner et al. 2000) and are sometimes seemingly contradictory (Amoros \& Bornette 2002). However it is well known that extant aquatic communities, which exist by virtue of organisms' adaptation to spatial and temporal variability, reflect the historical pattern of disturbance of a given site (Batzer \& Wissinger 1996). Accordingly, macroinvertebrate traits are most often used to explore this historical interplay although examples of studies focusing on aquatic vegetation traits (e.g., Bornette et al. 1994, Pautou \& Arens 1994, Henry et al. 1996) and fish traits (e.g., Persat et al. 1994, Poff \& Allan 1995) can be found. Examples of representative traits of macroinvertebrates that provide valuable information about how a community adapts to disturbances, either natural (e.g., river pulses) or anthropogenic (e.g., pollution), include potential size, life-span, number of reproductive cycles per year, resistance body-form and attachment to substrate, all of which potentially allow organisms to better resist disturbances and recuperate after a disturbance (Townsend \& Hildrew 1994, Usseglio-Polatera et al. 2000). In contrast, in stable areas less affected by such disturbances, biotic interactions become increasingly important (Wellborn et al. 1996). Consequently, functional traits proposed to change according to wetland characteristics include the proportion of organisms belonging to particular functional feeding groups, modes of reproduction, respiration and locomotion, life-history patterns and drift behavior (Usseglio-Polatera et al. 2000).

Many studies have focused on functional-trait responses to environmental gradients, most of which have studied longitudinal gradients (i.e., differences among sites situated along the river). However, relatively less information on the behaviour of such trait responses as a function of lateral gradients in disconnected floodplain wetlands is available, and most of the existing information on European floodplains is from the Rhône River, in France (e.g., Juget \& Lafont 1994, Richoux 1994, Tachet et al. 1994, Usseglio-Polatera 1994, Usseglio-Polaetra \& Tachet 1994, Paillex et al., 2007). Consequently, there is an unmet need to integrate the study of river and floodplain habitats to attain a complete understanding of trait patterns and processes along lateral gradients in other floodplains. Such understanding will further help to unify ecological assessment protocols and provide guidelines for managing and restoring river-floodplain ecosystems.

To this end, the present study focused on the relationships among environmental variables and species traits in a lateral hydrological connectivity gradient (i.e., from the river channel to isolated wetlands located further into the floodplain) across a Mediterranean river-floodplain (Ebro River, NE Spain). Our first objective was to identify significant differences in trait composition (i.e., abundance of functional groups), functional richness and functional diversity between wetlands aligned along a connectivity gradient. Based on the Intermediate Disturbance Hypothesis (Connell 1978), we would expect that wetlands located in an intermediate position in the hydrological connectivity gradient would show the highest functional diversity because both generalist and specialist organisms coexist there. On the other hand, a previous study developed in the Ebro basin has highlighted three main 
environmental gradients as important for aquatic invertebrates: hydrological connectivity, salinization and nutrient status (Gallardo et al. 2008). Our second objective was thus to analyze the influence of these environmental gradients on the functional-trait structure of macroinvertebrates inhabiting the Ebro floodplain. Additionally, we tested the suitability of using the functional grouping of invertebrates as bio-indicators of those gradients.

\section{Materials and methods}

\section{Study area}

The study area consisted of a 13-km segment of the Middle Ebro River floodplain in NE Spain (Fig. 1). The Ebro is a large Mediterranean river with an average discharge of $230 \mathrm{~m}^{3} \mathrm{~s}^{-1}$ in the study area. The environmental characteristics of the Ebro are similar to those of other Mediterranean rivers, which are distinguished by highly irregular flows caused by the high spatial and temporal variability of the Mediterranean climate (Gasith \& Resh 1999).
Four sites in the study area representing a range of lateral hydrological connectivity were monitored (Fig. 1). These include the River Site (RS) and three floodplain sites (oxbow lakes, OLs). OLs show similar habitat characteristics in terms of morphology, vegetation and substrate texture. They are small (35-70 ha) and shallow (0.5-2 m depth) former river meanders 42 to 61 years old that are separated from the river channel by a strip of riparian vegetation and a thick layer of sediment that limits groundwater seepage. Both the river site and oxbow lakes are surrounded by emergent vegetation, mostly Phragmites australis and Typha latifolia, but lack submergent vegetation.

The RS is located in the river channel; thus, it is permanently surface connected to the river flow. Lentic habitats sampled in the river become lotic at $200 \mathrm{~m}^{3} \mathrm{~s}^{-1}$. OLs are flooded at different flow limits reflecting a combination of distance to the river and channel embankment, and are thus arranged in a gradient of lateral hydrological connectivity. OL1, OL2 and OL3 became surface connected at $400 \mathrm{~m}^{3} \mathrm{~s}^{-1}, 800 \mathrm{~m}^{3} \mathrm{~s}^{-1}$ and $1200 \mathrm{~m}^{3} \mathrm{~s}^{-1}$, respectively. Therefore, connectivity decreased from the river site (RS) to floodplain sites located further into the floodplain, ranging from OL1 with high surface connectivity, to OL3 with low surface connectivity. Gallardo et al. (2008) and Cabezas et al. (2008) have provided a description of habitats and hydrological connectivity in each site.

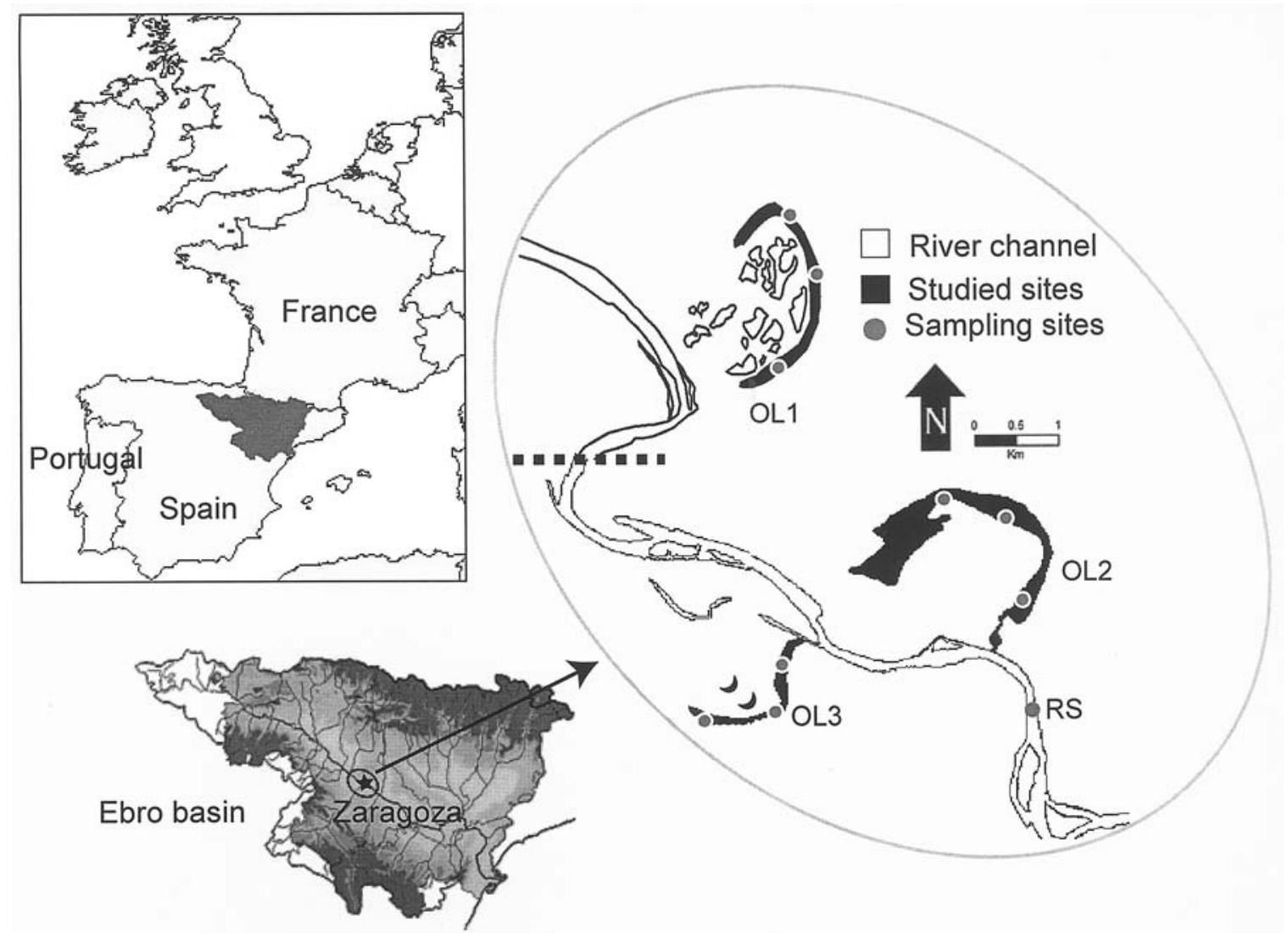

Fig. 1. Study site locations in the floodplain of the Middle Ebro River, Spain. The dashed line represents a separation of $13 \mathrm{~km}$ between sampling sites. OL, oxbow lake; RS, river site. 


\section{Sampling design and procedures}

In 2006, we collected bimonthly water and macroinvertebrate samples simultaneously. We established three sampling stations in OL1-3, and one sampling station in RS, for a total of 60 samples $(3$ OLs $\times 3$ sampling stations $\times 6$ dates; and $1 \mathrm{RS} \times 1$ sampling station $\times 6$ dates). Water samples for measurement of physical and chemical variables were collected in 2-liter polycarbonate bottles that were immediately refrigerated and transported to the laboratory, where they were filtered through precombusted $\left(450{ }^{\circ} \mathrm{C}\right.$ for $4 \mathrm{~h}$ ) Whatman ${ }^{\circledR} \mathrm{GF} / \mathrm{F}$ glass-fiber filters.
We collected invertebrate samples from various microhabitats within each site using a sweep net $(45 \times 45-\mathrm{cm}$ frame net, $500-\mu \mathrm{m}$ sieve, 1-min sampling). Samples were preserved in situ in $5 \%$ formalin. In the laboratory, samples were hand-sorted, and organisms were identified to the lowest taxonomical level, usually genus.

\section{Functional grouping of taxa}

We used the reference classification of invertebrates inhabiting European rivers developed by Usseglio-Polatera et al. (2000)

Table 1. Functional classification of invertebrates appearing in the Middle Ebro Floodplain.

\begin{tabular}{|c|c|c|c|}
\hline $\begin{array}{l}\text { Functional } \\
\text { group }\end{array}$ & Taxa included & Biological traits & \\
\hline Group "b" & $\begin{array}{l}\text { Atyaephira } \mathrm{sp} .(\mathrm{CRU}) \\
\text { Procambarus } \mathrm{sp} .(\mathrm{CRU}) \\
\text { Echinogammarus } \mathrm{sp} . \\
(\mathrm{CRU})\end{array}$ & $\begin{array}{l}\text { Corbicula sp. (BIV) } \\
\text { Unio sp. (BIV) } \\
\text { Ephoron sp. (EPH) } \\
\text { Helobdella } \text { sp. (HIR) }\end{array}$ & $\begin{array}{l}\text { Medium to large crawlers or burrowers using } \\
\text { various food sources and feeding habits. } \\
\text { Ovoviviparity reproduction, aquatic respiration } \\
\text { and dispersal }\end{array}$ \\
\hline Group “c”" & $\begin{array}{l}\text { Tipuloidea (DIP) } \\
\text { Hexatomini (DIP) } \\
\text { Limoniini (DIP) } \\
\text { Ceratopogonidae (DIP) }\end{array}$ & $\begin{array}{l}\text { Ephemera } \mathrm{sp} .(\mathrm{EPH}) \\
\text { Erpobdella } \mathrm{sp} .(\mathrm{HIR}) \\
\text { Rhyacopila } \text { sp. (TRI) }\end{array}$ & $\begin{array}{l}\text { Medium size, monovoltine crawlers. Cemented } \\
\text { eggs or clutches. Dormancy. Predators and } \\
\text { shredders. }\end{array}$ \\
\hline Group "d" & $\begin{array}{l}\text { Boyeria } \mathrm{sp} .(\mathrm{ODO}) \\
\text { Platycnemis } \mathrm{sp} .(\mathrm{ODO}) \\
\text { Coenagrion sp. (ODO) }\end{array}$ & $\begin{array}{l}\text { Trithemis } \mathrm{sp} .(\mathrm{ODO}) \\
\text { Ceriagrion } \mathrm{sp} .(\mathrm{ODO}) \\
\text { Chalcolestes } \mathrm{sp} .(\mathrm{COL})\end{array}$ & $\begin{array}{l}\text { Medium-large insects. Semivoltine with long life } \\
\text { cycles. Different reproduction techniques. Fliers, } \\
\text { thus aerial dispersal. Diapause, crawlers, feeding } \\
\text { on other macroinvertebrates. }\end{array}$ \\
\hline Group "e" & $\begin{array}{l}\text { Culicinae (DIP) } \\
\text { Ephydridae (DIP) } \\
\text { Eriopterini (DIP) } \\
\text { Chironomidae (DIP) } \\
\text { Simuliinae (DIP) } \\
\text { Ecnomus sp. (TRI) } \\
\text { Glossossoma sp. (TRI) } \\
\text { Cheumatopsyche sp. } \\
\text { (TRI) } \\
\text { Polycentropus sp.(TRI) }\end{array}$ & $\begin{array}{l}\text { Agraylea sp. (TRI) } \\
\text { Potamanthus sp.(TRI) } \\
\text { Micronecta } \text { sp. (HET) } \\
\text { Baetis sp. (EPH) } \\
\text { Cloeon sp. (EPH) } \\
\text { Ferrisia } \text { sp. (MOL) } \\
\text { Stagnicola } \text { sp. (MOL) } \\
\text { Physa sp. (MOL) } \\
\text { Planorbis sp. (MOL) } \\
\text { Theodoxus } \text { sp. (MOL) } \\
\text { Proasellus sp. (CRU) }\end{array}$ & $\begin{array}{l}\text { Small-medium size. Short life-cycle, uni- or } \\
\text { plurivoltines. Cemented eggs. Aquatic } \\
\text { respiration. Crawlers temporarily attached. } \\
\text { Shredder or scrapers or other habits. }\end{array}$ \\
\hline Group “f” & $\begin{array}{l}\text { Ecdyonurus sp. (EPH) } \\
\text { Caenis sp. (EPH) }\end{array}$ & & $\begin{array}{l}\text { Medium sized, monovoltine crawlers and } \\
\text { shredders. Cemented eggs and cocoons. Aquatic } \\
\text { respiration. }\end{array}$ \\
\hline Group "g” & $\begin{array}{l}\text { Glaenocorixa } \text { sp. (HET) } \\
\text { Parasigara } \text { sp. (HET) } \\
\text { Corixa } \text { sp. (HET) } \\
\text { Cymattia } \text { sp. (HET) } \\
\text { Microvelia } \text { sp. (HET) } \\
\text { Gerris } \text { sp. (HET) }\end{array}$ & $\begin{array}{l}\text { Mesovelia } \mathrm{sp} .(\mathrm{HET}) \\
\text { Dytiscus } \mathrm{sp} .(\mathrm{COL}) \\
\text { Ilibius } \mathrm{sp} .(\mathrm{COL}) \\
\text { Gyrinus } \mathrm{sp} .(\mathrm{COL}) \\
\text { Noterus } \mathrm{sp} .(\mathrm{COL})\end{array}$ & $\begin{array}{l}\text { Medium-small swimmers or crawlers. Shredders } \\
\text { and piercers, feeding on macroinvertebrates. } \\
\text { Aerial respiration, cemented clutches. Different } \\
\text { life cycle duration and reproductive cycles per } \\
\text { year. }\end{array}$ \\
\hline Group "h” & Nais sp. (OLI) & & $\begin{array}{l}\text { Different size, multivoltine, burrowers interstitial, } \\
\text { deposit feeders feeding on detritus or } \\
\text { microorganisms. Cocoons. Tegument respiration, } \\
\text { aquatic drift. }\end{array}$ \\
\hline
\end{tabular}

Data extracted from Usseglio-Polatera et al. (2000). No representative species of group "a" (Porifera and Bryozoa) were found. CRU, Crustacea; HIS, Hirudinea; MOL, Mollusca; BIV, Bivalvia; OLI, Oligochaeta; DIP, Diptera; EPH, Ephemeroptera; TRI, Trichoptera; ODO, Odonata; COL, Coleoptera; HET, Heteroptera. 
based on data from 472 genera. This classification includes eight uniform biological groups (from "a" to "h") based on 11 biological traits, extracted and modified from Tachet et al. (2000). Among these traits, the authors highlighted the maximum potential size, reproduction behavior (number of cycles per year, life-span and technique), respiration, locomotion, food source and feeding behavior as indicators of ecosystem stability, food web structure and biological interaction.

No representative species of group "a", composed of Porifera and Bryozoa, were found; thus the taxa appearing in the Ebro floodplains were classified into seven of these eight biological groups ("b" to "h"), whose composition and representative traits are summarized in Table 1. Only one species, Trithemis annulata, was not included in the reference classification of Usseglio-Polatera et al. (2000); it was included with the rest of the dragonflies in group " $d$ ".

After determining functional groups, we computed functional groups richness (FG richness, number of functional groups) and functional groups diversity, using the Simpson index (FG diversity $=1 / \Sigma p i_{2}$; where $p i$ was the proportion of individuals belonging to each functional group at a given site).

\section{Lateral environmental gradients}

Three main lateral environmental gradients have been described as affecting taxonomic structure of macroinvertebrates in the Middle Ebro floodplain (Gallardo et al. 2008), namely 1) hydrological disturbance, 2) confinement and 3) agricultural pressure. Based on the assumption that the functional structure at a local scale is driven by the same environmental factors than the taxonomic structure (Heino et al. 2007) the present study focuses on the response of the invertebrate traits to these three gradients.

\section{Hydrological disturbance}

In this paper, hydrological disturbance in each site and date was obtained by measuring three parameters that accounted for hydrological spatial and temporal variability: flood magnitude, flood duration and flood frequency (Table 2). These are defined as follows:

- Flood magnitude (FM) - water-column depth relative to the maximum and minimum water-column depths in the study period, calculated as

$$
\operatorname{FM}(\%)=\left(\mathrm{H}-\mathrm{H}_{\min }\right) 100 / \mathrm{H}_{\max },
$$

where $\mathrm{H}$ is the water-column depth of a site on the sampling day, and $\mathrm{H}_{\min }$ and $\mathrm{H}_{\max }$ are the minimum and maximum water-column depths, respectively, in the studied period. Water column depth was measured using pressure-based meters with 1-cm resolution (DI-241 Diver, Van Essen Instruments $\left.{ }^{\circledR}\right)$ installed in each site.

- Flood duration (FD) - number of days that the river flow rose above the established connection limit in a 365-day period before each sampling date in each site. For example, flood limit in OL1 is $400 \mathrm{~m}^{3} \mathrm{~s}^{-1}$. During one year (from 8 March 2005 to 8 March 2006) the river flow rose above $400 \mathrm{~m}^{3} \mathrm{~s}^{-1}$ on 36 days. Thus, this is the FD value for OL1 in 8 March 2006. The river flow was extracted from public available data (URL: http: //www.chebro.es). Flood limits were calculated from a digitalized elevation model (DEM) and validated in the field.

- Flood Frequency (FF) -considered as the number of flood events when the river flow rose above the established connection thresholds in a 365-day period before each sampling date in each site. Flood frequency differs from flood duration in that we considered the number of flood events independent of their duration. In the example above, nine flood events were recorded during one year after the sampling date (from 8 March 2005 to 8 March 2006). Thus, 9 is the FF value for OL1 in 8 March 2006.

No differences in these parameters were expected among the three sampling stations established in each OL, thus the same value of hydrological disturbance was assigned to them.

\section{Confinement}

The reduction in water turnover in wetlands that had reduced seepage, either because of river embankment or sediment accumulation, was considered here as "confinement". During confinement conditions, dissolved salts and organic nutrients from groundwater seepage, runoff and autogenic processes accumulate, enhancing primary productivity (Tockner et al. 1999). Therefore, an increase in the concentration of dissolved solids, chlorophyll- $a$ and dissolved organic nitrogen has been used to identify confinement situations (Table 2) as follows:

- Total Dissolved Salts (TDS) - determined from filtered water samples according to standard methods (APHA 1989).

- Chlorophyll-a (Chl.a) - Phytoplankton photosynthetic pigments were analyzed from water samples using the Spectrophotometric Method (APHA 1989).

- Dissolved Organic Nitrogen (DON) - assessed in filtered water samples with a continuous flow analyzer (FLOWSYSSYSTEA®)(APHA 1989).

Table 2. Mean (SD) values of hydrological and environmental descriptors in the Ebro River channel (RS) and three oxbow lakes (OL1-3).

\begin{tabular}{|c|c|c|c|c|c|}
\hline Variable & Abbreviation (units) & RS & OL1 & OL2 & OL3 \\
\hline Flood Duration & FD $\left(\mathrm{n}^{\circ}\right.$ days $\left.\mathrm{yr}^{-1}\right)$ & $88.33(13.46)$ & $31.82(4.91)$ & $2.40(1.24)$ & $0.83(0.38)$ \\
\hline Flood Frequency & $\mathrm{FF}\left(\mathrm{n}^{\mathrm{o}}\right)$ & $8.33(1.37)$ & $8.18(0.73)$ & $0.80(0.41)$ & $0.83(0.38)$ \\
\hline Flood Magnitude & FM $(\%)$ & $6.41(5.96)$ & $11.67(9.01)$ & $6.86(4.43)$ & $17.82(6.81)$ \\
\hline Total Dissolved Solids & TDS $\left(\mathrm{mg} \mathrm{L}^{-1}\right)$ & $1002(304)$ & $1779(952)$ & $1824(459)$ & $1929(759)$ \\
\hline Chlorophyll- $a$ & Chl.a $\left(\mu \mathrm{g} \mathrm{L}^{-1}\right)$ & $18.78(18.09)$ & $14.40(17.21)$ & $6.81(10.03)$ & $33.69(26.29)$ \\
\hline Dissolved Organic Nitrogen & $\mathrm{DON}\left(\mathrm{mg} \mathrm{L}^{-1}\right)$ & $0.36(0.44)$ & $0.11(0.20)$ & $0.12(0.45)$ & $0.29(0.27)$ \\
\hline Nitrate & $\mathrm{NO}_{3}^{-}\left(\mathrm{mg} \mathrm{L}^{-1}\right)$ & $16.00(4.60)$ & $1.82(3.11)$ & $42.94(6.97)$ & $1.42(3.12)$ \\
\hline
\end{tabular}

Variables in bold were significantly related to biological traits by multivariate analysis. 


\section{Agricultural pressure}

Agricultural seepage was a source of inorganic nutrients, mostly nitrate $\left(\mathrm{NO}_{3}^{-}\right)$that accumulates in OLs (Gallardo et al. 2008). Phosphate, which is usually related to agricultural impact, was not included here because it was always below the detection limit. Therefore, nitrate was used as an indicator of agricultural pressure (Table 2).

- Nitrate $\left(\mathrm{NO}_{3}^{-}\right)$- determined from filtered water samples analysed by ion chromatography (FLOWSYS-SYSTEA®) (APHA 1989).

\section{Data analyses}

A non-parametric analysis of variance (Kruskal-Wallis test, $\alpha=$ 0.05 ) was used to study differences among sites aligned along a gradient of lateral hydrological connectivity. Trait composition (abundance of each of seven functional groups), richness (FG richness) and diversity (FG diversity) were response variables, and the positions along the gradient of hydrological connectivity (RS, OL1, OL2 and OL3) were different levels of the independent variable (factor).

Multivariate ordination techniques were used to analyze the relationships among functional groups of invertebrates and environmental variables serving as surrogates for hydrological disturbance (FF, FD and FM), confinement (TDS, DON and Chl.a) and agricultural pressure $\left(\mathrm{NO}_{3}^{-}\right)$. Redundancy Analysis (RDA) was used because the length of the species gradient, assessed by Detrended Corresponded Analysis, was short (less than 2) and thus a linear relationship between species and environmental variables was expected (Legendre \& Legendre 1998). Environmental variables were previously $\log (X+1)$ transformed and checked to be un-correlated (Spearman correlation ratios $<0.6$ ). To avoid multi-collinearity problems we included in the RDA only those variables selected as significant by stepwise forward selection $(\alpha=0.05)$ and with inflation factors below 10 (ter Braak \& Smilauer 2002). Significance of the RDA model was assessed through permutation tests of the full model and by axis (Legendre \& Legendre 1998). All statistical analyses were run using R (version 2.5.1; R Development Core Team 2007).

\section{Results}

\section{Trait differences along a gradient of lateral hydrological connectivity}

We collected a total of 50,233 individuals belonging to 54 genera classified into seven functional groups. Taxonomic richness in functional groups varied from 19 taxa in group "e" and 11 taxa in group " $\mathrm{g}$ ", to only one in group "h" and three in group "f" (Table 1).

A decrease in total abundance coinciding with a decrease in surface connection established by the gradient of lateral hydrological connectivity was observed (Fig. 2 and Table 3). Moreover, non-parametric Kruskal-Wallis tests demonstrated that sites differed significantly in their invertebrate trait composition, richness and diversity (Fig. 2 and Table 3). Only the abundance of Groups "c" and "g" showed no significant differences among sites.

Six out of seven functional groups were present at the river site (RS). Among them, Groups "h" and "e" clearly dominated (Fig. 2). Functional groups inhabiting the RS included insects belonging to Diptera, Trichoptera, Heteroptera and Coleoptera families, and also aquatic oligochaetes. Group "d", composed of predatory dragonflies, was the only group not present in RS. Group "e" was dominant in OL1 and OL3, and Group "b", which includes most of the non-insect taxa, dominated OL2 (the OL located at an intermediate position along the connectivity gradient) (Fig. 2).

Functional groups richness varied significantly along the gradient of lateral hydrological connectivity (Table 3), being highest in RS and decreasing in OLs from OL1 to OL3 (Fig. 3). Functional groups diversity

Table 3. Mean (SD) values of functional groups abundance, richness and diversity in the Ebro river channel (RS) and three oxbow lakes (OL1-3).

\begin{tabular}{|c|c|c|c|c|c|c|c|c|}
\hline \multirow[t]{2}{*}{ Variable } & \multirow[t]{2}{*}{ Units } & \multirow[t]{2}{*}{$\mathbf{R S}$} & \multirow[t]{2}{*}{ OL1 } & \multirow[t]{2}{*}{ OL2 } & \multirow[t]{2}{*}{ OL3 } & \multicolumn{3}{|c|}{ Kruskal-Wallis } \\
\hline & & & & & & $\chi^{2}$ & d.f. & $p$ \\
\hline Group "b" & (CPUE) & $4.00(4.19)$ & $4.24(7.80)$ & $53.53(128.7)$ & $8.06(32.94)$ & 23.35 & 3 & $<0.001$ \\
\hline Group "c" & (CPUE) & $3.33(5.82)$ & $1.12(2.69)$ & $0.33(0.82)$ & $0.44(1.04)$ & 5.62 & 3 & 0.13 \\
\hline Group “d” & (CPUE) & $0.00(0.00)$ & $6.94(19.65)$ & $0.13(0.35)$ & $0.67(1.28)$ & 8.20 & 3 & 0.04 \\
\hline Group "e" & (CPUE) & $513.2(502.4)$ & $253.3(567.3)$ & $19.30(19.92)$ & $28.05(33.02)$ & 20.02 & 3 & $<0.001$ \\
\hline Group “f” & (CPUE) & $8.00(8.65)$ & $37.24(94.85)$ & $0.07(0.26)$ & $0.33(0.97)$ & 21.09 & 3 & $<0.001$ \\
\hline Group “g” & (CPUE) & $21.50(52.18)$ & $0.06(0.24)$ & $0.07(0.26)$ & $0.11(0.47)$ & 5.07 & 3 & 0.17 \\
\hline Group “h” & (CPUE) & $4031(4559)$ & $31.65(33.74)$ & 13.67 (17.29) & $14.56(26.21)$ & 22.30 & 3 & $<0.001$ \\
\hline $\mathrm{N}$ & (CPUE) & $4581(4510)$ & $334.5(593.6)$ & $87.10(138.84)$ & $52.21(71.58)$ & 23.99 & 3 & $<0.001$ \\
\hline FG richness & $\mathrm{N}^{\circ}$ groups & $4.67(0.51)$ & $3.94(1.20)$ & $3.33(0.49)$ & $2.78(1.06)$ & 17.62 & 3 & 0.001 \\
\hline FG diversity & & $1.25(0.18)$ & $1.82(0.63)$ & $2.12(0.51)$ & $1.73(0.54)$ & 10.20 & 3 & 0.02 \\
\hline
\end{tabular}

Results of non-parametric analysis of variance between each biological descriptor and the position along the gradient are shown. $\mathrm{N}$, total invertebrate abundance; FG richness, number of functional groups; FG diversity, Simpson diversity of functional groups; $p=$ significance value; CPUE, catches per unit effort; $\chi^{2}$, Chi-squared distribution, d.f., degrees of freedom. 


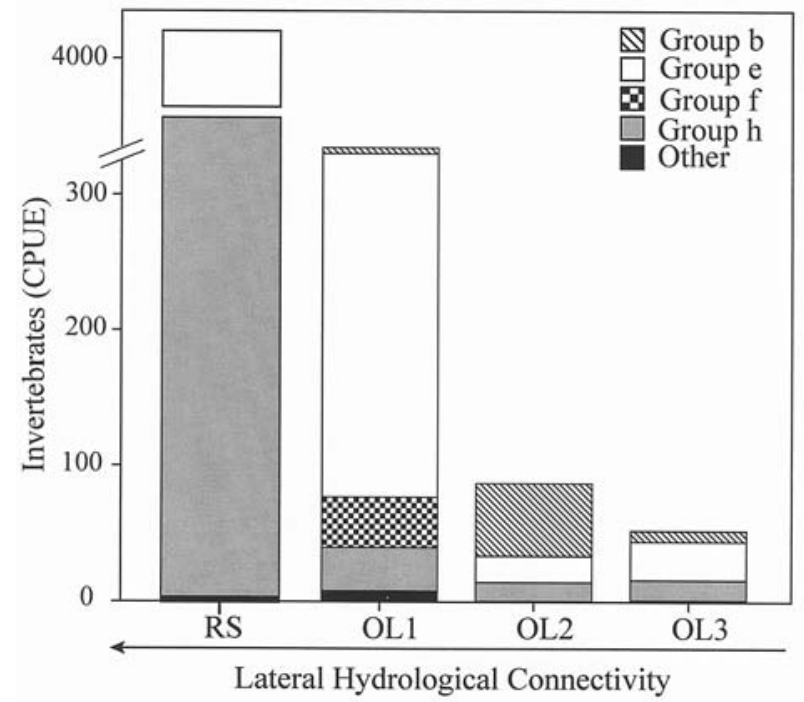

Fig. 2. Functional groups composition of the Ebro River (RS) and three oxbow lakes (OL1-3). Characteristics and taxonomic composition of functional groups are summarized in Table 1. CPUE, catches per unit effort (see description in text). "Other" includes Groups "c", "d" and "g" which accounted for less than $5 \%$ of the total macroinvertebrate abundance.

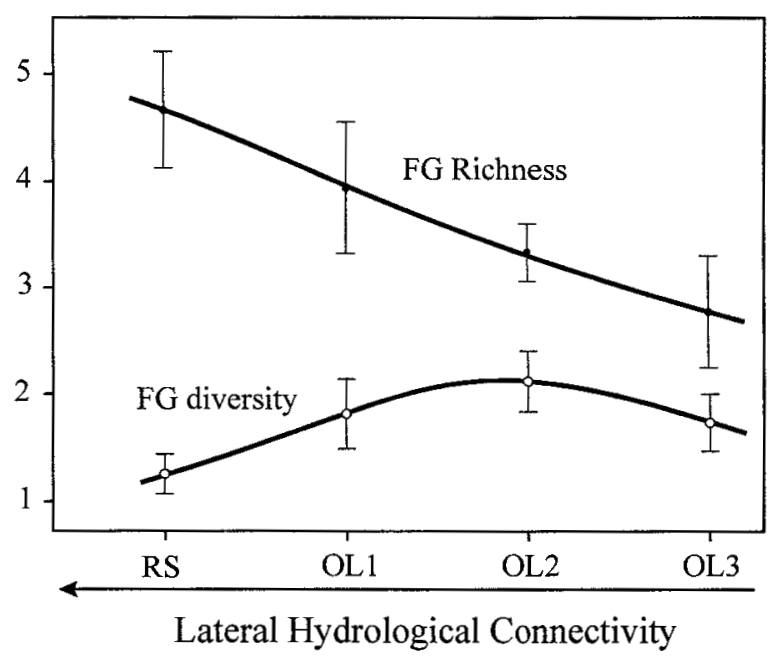

Fig. 3. Functional groups richness (FG richness, number of functional groups) and functional groups diversity (FG diversity, Simpson index of diversity groups) in the Ebro River (RS) and three oxbow lakes (OL1-3). also varied significantly across the connectivity gradient (Table 3), but showed a different pattern, peaking in OL2 (intermediate wetland in the connectivity gradient), where functional groups diversity was two times higher than in the RS (Fig. 3).

\section{Relationship between lateral gradients and invertebrate biological traits}

Significant variables extracted by forward selection included nitrate, dissolved solids, flood duration and frequency $\left(\mathrm{NO}_{3}^{-}\right.$, TDS, FD and FF). RDA performed on abundance of seven functional groups and these four selected variables was highly significant (Permutation Test on the full model, $\mathrm{p}<0.005$ ); with the first two axes explaining $43 \%$ of invertebrate variability (Permutation Test by axis, $\mathrm{p}<0.005$ ). At least one variable of each lateral gradient considered was selected (Table 4).

The first RDA axis was related to flood duration and frequency (FD and FF), which were surrogates for hydrological disturbance. Hydrological disturbance was highest in RS and decreased in OLs from OL1 to OL3 (Fig. 4).

The second RDA axis was negatively related to nitrate concentration $\left(\mathrm{NO}_{3}^{-}\right)$, a surrogate of agricultural pressure. OL2, where agricultural pressure was more intense, showed the highest concentrations of $\mathrm{NO}_{3}^{-}$ (up to $50 \mathrm{mg} \mathrm{L}^{-1}$ ). Nitrate concentration was also high in RS (up to $20 \mathrm{mg} \mathrm{L}^{-1}$ ) because of extensive agricultural pressure on the watershed as a whole. In contrast, nitrate concentration was low in OL1 and OL3 $\left(<5 \mathrm{mg} \mathrm{L}^{-1}\right)$. Wetlands were arranged in a longitudinal hydrological gradient in second RDA axis, from OL1 situated upstream to OL3, OL2 and RS sites situated progressively downstream.

Total dissolved salts (TDS), the surrogate of confinement, was weakly related to both RDA1 (hydrological disturbance) and RDA2 (agricultural pressure) (Table 4). Highly confined sites, such as OL3, were isolated from both the river pulses and sewage coming from agriculture fields; OL2 and OL1 were less confined because of higher water-table variability.

Table 4. Results of redundancy analysis performed using four environmental variables (explanatory variables) and abundance of seven functional groups of macroinvertebrates (response variables).

\begin{tabular}{lrr}
\hline & RDA1 & RDA2 \\
\hline Nitrate concentration & 0.04 & -0.93 \\
Total dissolved solids concentration & -0.28 & 0.31 \\
Flood duration & 0.83 & 0.23 \\
Flood frequency & 0.70 & 0.44 \\
Accumulated variability accounted for by each RDA-axis & $\mathbf{3 3 \%}$ & $\mathbf{4 3 \%}$ \\
\hline
\end{tabular}




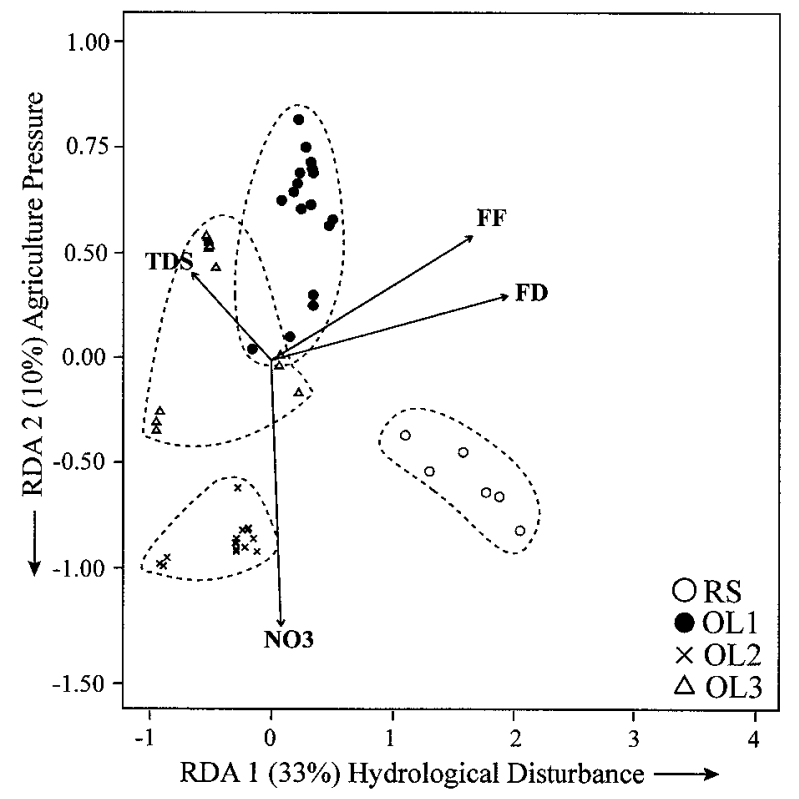

Fig. 4. Results of Redundancy Analysis performed between abundance of seven functional groups and four environmental variables. Variables were previously selected by forward selection $(\alpha=0.05)$. TDS, total dissolved solids concentration; NO3, nitrate concentration; FF, flood frequency; FD, flood duration; RS, River site; OL, oxbow lake.

\section{Functional traits as bio-indicators of environmental gradients}

To identify potential bio-indicators of hydrological disturbance and agricultural pressure, we projected the optima (maximum density) and distribution of functional groups onto the first and second RDA-axis, respectively (Fig. 5). We found that Group "g" was related to both hydrological and agricultural disturbance. This group included aquatic bugs and coleopters that were small in size or exhibited multivoltinism. Beyond these, aquatic worms included in Group " $h$ " peaked at highly hydrologically disturbed sites (i.e., those highly influenced by the river), while crustaceans and bivalves of Group " $b$ " peaked at sites affected by agricultural sewage.

\section{Discussion}

\section{Trait differences along a gradient of lateral hydrological connectivity}

High spatial heterogeneity and diverse food resources enhanced richness of functional groups in the river
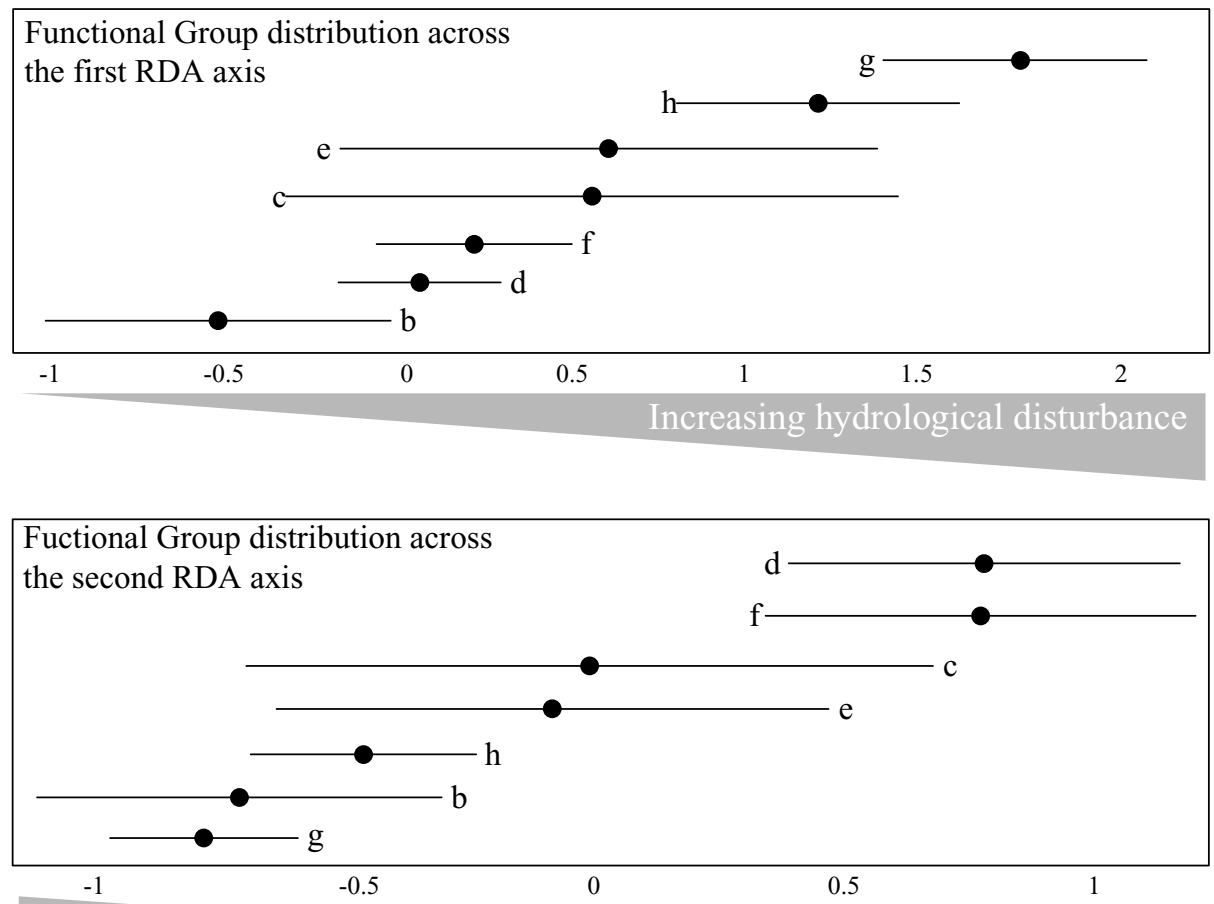

Increasing agricultural pressure

Fig. 5. Functional groups distribution across main environmental gradients identified after Redundancy Analysis in the Middle Ebro Floodplain. Mean groups distribution (optima) is represented by black dots; black lines represent the standard deviation of the groups' distribution. 
channel, but only certain combinations of traits dominated the river community given its particular environmental conditions (e.g., Oligochaeta in Group "h" and Chironomidae in Group "e", which dominated the river channel). As reported by several authors, disturbance frequency in the river channel selects for those traits that allow organisms to adapt to a changing environment and to recuperate faster after disturbance, such as short life cycles, asexual reproduction, multiple cycles per year, substrate-attachment forms, and crawling or burrowing locomotion (Townsend \& Hildrew 1994, Townsend et al. 1997a, Townsend et al. 1997b, Usseglio-Polatera et al. 2000). Based on the work of these authors, we should have expected to find that species in the river channel were highly specialized in their feeding behavior, typically filter feeders and scrapers that fed on suspended particles and algae. In contrast, we found a river community that was highly diversified with respect to their feeding behavior, and included predators, shredders, piercers, scrapers and deposit feeders. According to Scarsbrook \& Townsend (1993), this situation could reflect a combination of low disturbance frequency and high habitat heterogeneity, and thus high refuge and resource availability that would allow species with different feeding behavior to coexist.

As we move from the river channel to disconnected wetlands within the floodplain, we expect to find that the influence of hydrological disturbance decreases while biotic interactions become increasingly important (Wellborn et al. 1996). Consequently, hydrological stability in floodplain wetlands should allow organisms to reach large sizes and attain long life spans, whereas closer biotic interaction would force them to diversify their feeding behaviour, reproduction and locomotion techniques (Townsend \& Hildrew 1994, Townsend et al. 1997a, Townsend et al. 1997b, Usseglio-Polatera et al. 2000). In accordance with these ideas, we found that crustaceans, bivalves and some insects (e.g., Odonata and Coleoptera larvae) were representative taxonomic inhabitants of the disconnected floodplain wetlands. They were mostly large-sized shredders, filterers and piercers that fed on the wide variety of detritus and macrophytes available, and also predators that fed on other invertebrates.

It is worth highlighting, however, that several functional groups showing adaptation to disturbance (e.g., small size, attachment to substrate, multivoltinism, cemented eggs or clutches, filter-feeding, crawling and burrowing) in Groups "e" and "g" were present in both the river channel and floodplain wetlands, but with differing degrees of dominance. This suggests that organ- isms dominating the river channel were transported during floods to floodplain wetlands, where they found refuge but did not reach high densities. Generalist species that could have benefited from river pulses to colonize new habitats included Ecnomus sp., Micronecta sp., and Nais sp. In contrast, specialist species present in the studied floodplain wetlands that did not appear in the river channel included the predatory dragonflies, Boyeria sp., Trithemis sp. and Coenagrion sp. Consistent with our expectations and in accordance with the intermediate disturbance hypothesis (Connell 1978), the diversity of functional groups was highest at floodplain wetlands exhibiting an intermediate level of disturbance, where both types of species coexisted (i.e. generalist and specialist).

It is worth noting that important habitats, such as secondary channels, backwaters, temporary groundwater-fed pools and hydrologically inter-connected water-bodies were absent in our study area. However, the selected floodplain wetlands represent a unique type of ecosystem (oxbow lake) and cover a range of spatial and temporal hydrological connectivity characteristic of floodplains of large rivers worldwide. Moreover, despite the short lateral hydrological gradient studied here, we found a significant response of macroinvertebrate trait composition, richness and diversity. Such findings underscore the importance of every connectivity type (longitudinal and lateral) in the structure and functionality of the whole river floodplain system (Amoros \& Bornette 2002).

\section{Relationships between lateral gradients and invertebrate biological traits}

The classification of organisms into functional groups was beneficial for the analysis of the functional adaptation of invertebrates to environmental gradients. As such, it was helpful in disentangling the response of several biological traits to lateral environmental and hydrological gradients (Usseglio-Polatera et al. 2000). Our results are in agreement with this relationship as reflected by the fact that the main environmental gradients (hydrological disturbance and agricultural pressure) significantly affected invertebrate functionality.

Previous studies analyzing taxonomic patterns have identified limitations in discriminating pressure effects, for example between hydrological, physico-chemical and trophic gradients (Gallardo et al. 2008). These difficulties reflect the fact that hydrological connectivity involves multiple patterns and processes, including the superficial transport of suspended solids, seepage input of dissolved solids, accumulation of organic 
matter during confinement and export of organic matter during large, erosive floods (Tockner et al. 1999). An analysis of these processes can be confounded by confinement-related effects and agricultural pressures, which also involve changes in salts and nutrients. In contrast, the present study found that functional traits were useful in discriminating environmental gradients, showing that increasing disturbance, either hydrological or agricultural, led to domination by Group " $\mathrm{g}$ " including organisms with small size, multiple cycles per year and asexual reproduction. The presence of these functional traits reflected the adaptation of communities to frequent and intense disturbance, as suggested by other authors (Doledec et al. 2006, Mellado et al. 2008). Furthermore, agricultural pressure and hydrological disturbance could be discriminated from one another on the basis of the abundance of Group " $b$ " and Group "h", respectively.

Beyond hydrology and water chemistry, the remaining variability in invertebrate traits could be related to several unmeasured variables, such as habitat characteristics (e.g., vegetation cover and substrate size) and biotic interaction (e.g., fish predation and competition with other species) (Batzer \& Wissinger 1996, Wellborn et al. 1996). Nevertheless, the studied gradients explained almost $50 \%$ of the existing variability in the trait structure, and each of the gradients has been shown to be important in explaining the trait structure.

\section{The functional classification of macroinvertebrates: a tool for identifying bio- indicators}

Given the large number of biological and ecological traits that could be related to environmental gradients - there are more than 50 biological and 60 ecological trait categories in the bibliography - the classification of organisms into a limited number of homogeneous groups strongly simplifies their use. Invertebrates included in each functional group are expected to have similar life-histories and behavior, and thus show the same response to main environmental gradients (Statzner 2001). However, our results showed that some functional groups have wide distributions (e.g., Group "c"; Fig. 5), so we should take these indicators with caution. A point to note is that the species in each group are not the same as those in the original classification of Usseglio-Polatera et al. (2000), but only include those present in our study area. Therefore, more studies are needed to better assess the ability of each functional group to indicate environmental gradients or human impacts.
Another point to note is that a complex combination of traits was represented by each functional group, and thus the direct relationships between particular traits (e.g., size, feeding habitats) and environmental gradients were difficult to identify. To achieve a better understanding of how spatial and environmental gradients act as a template for macroinvertebrate structure and functionality in complex floodplain ecosystems, future investigations should evaluate the separate effects of lateral gradients on particular traits.

Finally, it is worth highlighting the fact that, despite their key role in river-floodplain processes and ecosystem biodiversity (Amoros \& Roux 1988, Ward \& Stanford 1995, Tockner et al. 1999, Amoros \& Bornette 2002), floodplain habitats considered as those disconnected wetlands located in the floodplain, have been systematically ignored in ecological assessments of large rivers in Europe. We believe that future studies should reinforce the potential of the functional grouping of invertebrates to assess ecological integrity in river-floodplain habitats considered as a whole.

\section{Acknowledgements}

This study was supported by the Spanish Ministry of Education (MEC CGL2005-07059-C02-01) and Department of Environment-Aragon Government, with additional support for B. G. from the Aragon Government (B061 2005 pre-doctoral grant) to A. C. and to M. G. from the Spanish Ministry of Education and Sciences from the Spanish Scientific Council (I3P pre-doctoral grant) (FPI pre-doctoral grant). Thanks are extended to Sylvain Dolédec and two anonymous referees for their helpful comments and suggestions.

\section{References}

Amoros, C. \& Bornette, G., 2002: Connectivity and biocomplexity in waterbodies of riverine floodplains. - Freshwat. Biol. 47: 761-776.

Amoros, C. \& Roux, A. L., 1988: Interaction between large water bodies within the floodplain of large rivers: function and development of connectivity. - Münst. Geo. Arb. 29: 125-130.

APHA (eds), 1989: Standard methods for the examination of water and wastewater. - Washington D. C., USA, pp $1-1715$.

Bady, P., Doledec, S., Fesl, C., Gayraud, S., Bacchi, M. \& Scholl, F., 2005: Use of invertebrate traits for the biomonitoring of European large rivers: the effects of sampling effort on genus richness and functional diversity. - Freshwat. Biol. 50: 159-173.

Batzer, D. P. \& Wissinger, S. A., 1996: Ecology of insect communities in nontidal wetlands. - Annu. Rev. Entomol. 41: 75-100. 
Bornette, G., Henry, C., Barrat, M. H. \& Amoros, C., 1994: Theoretical Habitat Templets, Species Traits, and Species Richness - Aquatic Macrophytes in the Upper Rhone River and Its Floodplain. - Freshwat. Biol. 31: 487-505.

Cabezas, A., González, E., Gallardo, B., García, M., González, M. \& Comín, F. A., 2008: Effects of hydrological connectivity on the substrate and understory structure of riparian wetlands in the Middle Ebro River (NE Spain): Implications for restoration and management. - Aquat. Sci. 10.1007/s00027008-8059-4.

Connell, J. H., 1978: Diversity in Tropical Rain Forests and oral Reefs - High Diversity of Trees and Corals Is Maintained Only in a Non-Equilibrium State. - Science 199: 1302-1310.

Doledec, S., Phillips, N., Scarsbrook, M., Riley, R. H. \& Townsend, C. R., 2006: Comparison of structural and functional approaches to determining landuse effects on grassland stream invertebrate communities. - J. N. Amer. Benthol. Soc. 25: 44-60.

Doledec, S. \& Statzner, B., 2008: Invertebrate traits for the biomonitoring of large European rivers: an assessment of specific types of human impact. - Freshwat. Biol. 53: 617-634.

Doledec, S., Statzner, B. \& Bournard, M., 1999: Species traits for future biomonitoring across ecoregions: patterns along a human-impacted river. - Freshwat. Biol. 42: 737-758.

Galat, D. L., Fredrickson, L. H., Humburg, D. D., Bataille, K. J., Bodie, J. R., Dohrenwend, J., Gelwicks, G. T., Havel, J. E., Helmers, D. L., Hooker, J. B., Jones, J. R., Knowlton, M. F., Kubisiak, J., Mazourek, J., McColpin, A. C., Renken, R. B. \& Semlitsch, R. D., 1998: Flooding to restore connectivity of regulated, large-river wetlands - Natural and controlled flooding as complementary processes along the lower Missouri River. - Bioscience 48: 721-733.

Gallardo, B., García, M., Cabezas, A., González, E., González, M., Ciancarelli, C. \& Comín, F. A., 2008: Macroinvertebrate patterns along environmental gradients and hydrological connectivity within a regulated river-floodplain. - Aquat. Sci. 70: $248-258$.

Gasith, A. \& Resh, V. H., 1999: Streams in Mediterranean climate regions: Abiotic influences and biotic responses to predictable seasonal events. - Annu. Rev. Ecol. Syst. 30: 51-81.

Gayraud, S., Statzner, B., Bady, P., Haybach, A., Scholl, F., Usseglio-Polatera, P. \& Bacchi, M., 2003: Invertebrate traits for the biomonitoring of large European rivers: an initial assessment of alternative metrics. - Freshwat. Biol. 48: 20452064.

Heino, J., Mykra, H., Kotanen, J. \& Muotka, T., 2007: Ecological filters and variability in stream macroinvertebrate communities: do taxonomic and functional structure follow the same path? - Ecography 30: 217-230.

Henry, C. P., Amoros, C. \& Bornette, G., 1996: Species traits and recolonization processes after flood disturbances in riverine macrophytes. - Vegetatio 122: 13-27.

Juget, J. \& Lafont, M., 1994: Theoretical habitat templets, species traits, and species richness - aquatic oligochaetes in the Upper Rhone River and its floodplain. - Freshwat. Biol. 31: 327-340.

Junk, W. J., 1989: The Use of Amazonian Floodplains under an Ecological Perspective. - Interciencia 14: 317-322.

Legendre, P. \& Legendre, L., 1998: Numerical ecology. - Elsevier Science, Amsterdam, pp 1-853.
Mellado, A., Alonso, M. L. S. \& Gutierrez, M. R. V.-A., 2008: Biological traits of stream macroinvertebrates from a semiarid catchment: patterns along complex environmental gradients. - Freshwat. Biol. 53: 1-21.

Paillex, A., Castella, E. \& Carron, G., 2007: Aquatic macroinvertebrate response along a gradient of lateral connectivity in river floodplain channels. - J. N. Amer. Benthol. Soc. 26: 779-796.

Pautou, G. \& Arens, M. F., 1994: Theoretical habitat templets, species traits, and species richness - floodplain vegetation in the Upper Rhone River. - Freshwat. Biol. 31: 507-522.

Persat, H., Olivier, J. M. \& Pont, D., 1994: Theoretical habitat templets, species traits, and species richness - fish in the Upper Rhone River and its floodplain. - Freshwat. Biol. 31: 439-454.

Poff, N. L. \& Allan, J. D., 1995: Functional-Organization of Stream Fish Assemblages in Relation to Hydrological Variability. - Ecology 76: 606-627.

R Development Core Team, 2007: R : A language and environment for statistical computing. - Foundation for Statistical Computing (http://www.R-project.org), Vienna, Austria.

Richoux, P., 1994: Theoretical habitat templets, species traits, and species richness - aquatic Coleoptera in the Upper Rhone River and its floodplain. - Freshwat. Biol. 31: 377-395.

Scarsbrook, M. R. \& Townsend, C. R., 1993: Stream Community Structure in Relation to Spatial and Temporal Variation - a Habitat Templet Study of 2 Contrasting New-Zealand Streams. - Freshwat. Biol. 29: 395-410.

Smith, A. J., Bode, R. W. \& Kleppel, G. S., 2007: A nutrient biotic index (NBI) for use with benthic macroinvertebrate communities. - Ecological Indicators 7: 371-386.

Statzner, B., 2001: Perspectives for biomonitoring at large spatial scales: a unified measure for the functional composition on invertebrate communities in European running waters. Basic Appl. Ecol. 2: 73-85.

Statzner, B., Bady, P., Doledec, S. \& Scholl, F., 2005: Invertebrate traits for the biomonitoring of large European rivers: an initial assessment of trait patterns in least impacted river reaches. - Freshwat. Biol. 50: 2136-2161.

Tachet, H., Richoux, M., Bournaud, M. \& Usseglio-Polatera, P. (eds.), 2000: Invertebrés d'eau douce. - CNRS, pp. 1-588

Tachet, H., Usseglio-Polatera, P. \& Roux, C., 1994: Theoretical habitat templets, species traits, and species richness Trichoptera in the Upper Rhone River and its floodplain. Freshwat. Biol. 31: 397-415.

ter Braak, C. J. F. \& Smilauer, P. (eds.), 2002: CANOCO Reference manual and CanoDraw for Windows User's guide: Software for Canonical Community Ordination (version 4.5). Micro Power Ithaca, USA, pp 1-500

Tockner, K., Pennetzdorfer, D., Reiner, N., Schiemer, F. \& Ward, J. V., 1999: Hydrological connectivity, and the exchange of organic matter and nutrients in a dynamic river-floodplain system (Danube, Austria). - Freshwat. Biol. 41: 521-535.

Tockner, K., Malard, F. \& Ward, J. V., 2000: An extension of the flood pulse concept. - Hydrol. Process. 14: 2861-2883.

Townsend, C. R. \& Hildrew, A. G., 1994: Species traits in relation to a habitat templet for river systems. - Freshwat. Biol. 31: 265-275.

Townsend, C. R., Doledec, S. \& Scarsbrook, M. R., 1997a: Species traits in relation to temporal and spatial heterogeneity in streams: A test of habitat templet theory. - Freshwat. Biol. 37: $367-387$. 
Townsend, C. R., Scarsbrook, M. R. \& Doledec, S., 1997b: Quantifying disturbance in streams: alternative measures of disturbance in relation to macroinvertebrate species traits and species richness. - J. N. Amer. Benthol. Soc. 16: 531-544.

Usseglio-Polatera, P., 1994: Theoretical habitat templets, species traits, and species richness - aquatic insects in the Upper Rhone River and its floodplain. - Freshwat. Biol. 31: 417-437.

Usseglio-Polatera, P., Bournaud, M., Richoux, P. \& Tachet, H., 2000: Biological and ecological traits of benthic freshwater macroinvertebrates: relationships and definition of groups with similar traits. - Freshwat. Biol. 44: 563-568.

Submitted: 14 July 2008; accepted: 7 November 2008.
Usseglio-Polatera, P. \& Tachet, H., 1994: Theoretical habitat templets, species traits, and species richness - Plecoptera and Ephemeroptera in the Upper Rhone River and its floodplain. - Freshwat. Biol. 31: 357-375.

Ward, J. V. \& Stanford, J. A., 1995: Ecological Connectivity in Alluvial River Ecosystems and Its Disruption by Flow Regulation. - Regul. Riv. 11: 105-119.

Wellborn, G. A., Skelly, D. K. \& Werner, E. E., 1996: Mechanisms creating community structure across a freshwater habitat gradient. - Annu. Rev. Ecol. Syst. 27: 337-363. 